\title{
Nitric oxide and cardiovascular disease
}

\author{
Martin McIntyre, Anna F Dominiczak
}

\begin{abstract}
Summary
Endothelium-derived nitric oxide is an important regulatory molecule in cardiovascular function. Reduced availability of nitric oxide has been implicated in the pathogenesis of hypertension and atherosclerosis.
\end{abstract}

Keywords: nitric oxide, hypertension, atherosclerosis

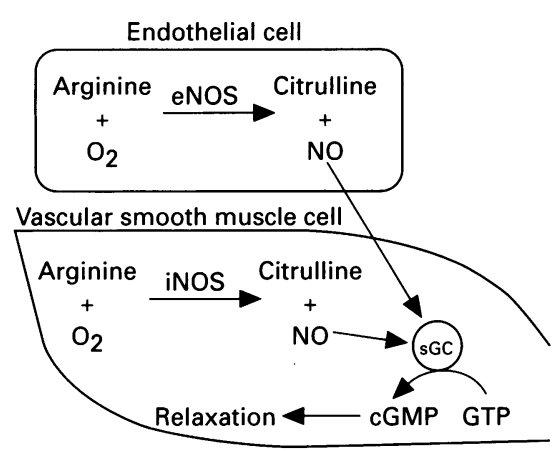

Figure 1 Mechanism of action of endothelium-derived nitric oxide. sGC, soluble guanylate cyclase; GTP, guanosine triphosphate; cGMP, cyclic guanosine monophosphate; LDL, low-density lipoprotein

University Department of Medicine and Therapeutics, Gardiner Institute, Western Infirmary, Glasgow G11 6NT, UK

M McIntyre

AF Dominiczak

Correspondence to Anna F Dominiczak

Accepted 25 September 1996
Traditionally, the endothelium had been regarded simply as a passive barrier lining blood vessels. However, in 1980, Furchgott and Zawadski elegantly demonstrated that the endothelium was important in vascular relaxation by releasing an endothelium-derived relaxing factor (EDRF). ${ }^{1}$ The precise identity of EDRF remained elusive until 1987 when Palmer et al showed that EDRF was the simple diatomic molecule nitric oxide (NO). ${ }^{2}$ Since then there has been an explosion of research in this field. It is now accepted that, among its many roles, NO is an important regulatory molecule in cardiovascular function, maintaining tone in normal blood vessels. ${ }^{3}$

NO is synthesised in vascular endothelial cells from the abundant amino acid L-arginine by the enzyme endothelial nitric oxide synthase (eNOS). The enzyme is constitutively expressed, and is therefore always present in endothelial cells. However, its activity is tightly controlled by intracellular calcium levels. ${ }^{4}$ Endothelium-dependent vasodilators such as acetylcholine act by increasing intracellular calcium, thereby increasing eNOS activity and thus NO release. eNOS belongs to a family of isoenzymes which also includes the inducible form (iNOS) which is not normally present in cells, but can be induced in vascular smooth muscle cells, macrophages and other tissues by cytokines and bacterial endotoxin. The third member of the family is brain NOS (bNOS), another constitutively expressed, calcium-dependent, isoform found in the brain and peripheral nervous system (table 1, see ref 5 for review).

The NO produced by vascular endothelial cells diffuses to the smooth muscle layer where it stimulates the enzyme soluble guanylate cyclase (sGC) to produce cyclic guanosine monophosphate (cGMP) and causes vasorelaxation ${ }^{2}$ (figure 1). Endothelium-derived NO can be stimulated by shear stress on the endothelial cells caused by increased blood flow. This is thought to be one of the mechanisms whereby physical exercise improves endothelial function and cardiovascular function in general. ${ }^{6}$

\section{Nitric oxide and essential hypertension}

Human essential hypertension is characterised by increased total peripheral resistance. As NO is an endogenous vasodilator, there are theoretical reasons why a deficiency of NO may contribute to increased total peripheral resistance. In addition, NO causes renal vasodilatation with consequent diuresis and natriuresis. ${ }^{7}$ These actions would tend to lower blood pressure, therefore a reduction in this mechanism is another way in which NO deficiency may theoretically contribute to hypertension.

Many investigators have employed forearm venous occlusion plethysmography to measure endothelial function in patients with essential hypertension and compare it to normotensive controls. Several studies have demonstrated impaired endothelial function in hypertensive patients. ${ }^{8-12}$ However, the issue is still controversial as other studies suggest that this is not always the case ${ }^{13,14}$ (table 2). This controversy may reflect the fact that essential hypertensives represent a heterogenous group in whom a small, as yet undefined, subgroup may have NO deficiency while others have normal or even increased NO release as a compensatory mechanism. In any case, such studies cannot prove that NO deficiency is primary and causal rather than secondary to the effects of high blood pressure which can itself damage the endothelium.

The clearest evidence that NO is important in blood pressure regulation comes from studies which manipulate the L-arginine/NO pathway. Although

Table 1 Nitric oxide synthase (NOS) isoenzymes

\begin{tabular}{lll}
\hline Old nomenclature & New nomenclature & Expression \\
\hline Brain NOS & NOS I & Constitutive \\
Inducible NOS & NOS II & Inducible \\
Endothelial NOS & NOS III & Constitutive \\
\hline
\end{tabular}


Table 2 Comparison of vascular responses to different interventions between hypertensive $(\mathrm{Ht})$ and normotensive $(\mathrm{Nt})$ subjects. $\mathrm{ACh}$, acetylcholine; LNMMA, $N^{\mathrm{G}}$-monomethyl-L-arginine Reproduced from ref 15

\begin{tabular}{llll}
\hline Vasculature studied & Intervention & Relative vascular response & Ref \\
\hline Forearm & $\mathrm{ACh}$ & $\mathrm{Ht}<\mathrm{Nt}$ & 8 \\
Forearm & $\mathrm{ACh}$ & $\mathrm{Ht}<\mathrm{Nt}$ & 9 \\
Coronary & $\mathrm{Ht}<\mathrm{Nt}$ & 10 \\
Forearm & $\mathrm{ACh}$ & $\mathrm{Ht}<\mathrm{Nt}$ & 11 \\
Forearm & $\mathrm{Ht}$ & $\mathrm{Ht}<\mathrm{Nt}$ & 12 \\
Forearm & $\mathrm{Ht}=\mathrm{Nt}$ & 13 \\
Brachial artery & ACh or carbachol & $\mathrm{Ht}=\mathrm{Nt}$ & 14 \\
\hline
\end{tabular}

thought not to be rate limiting for the eNOS enzyme, the administration of exogenous L-arginine has been shown to reduce blood pressure in normo- and hypertensive subjects. ${ }^{16}$ Conversely, despite the fact that there are many factors which control blood pressure, chronic inhibition of NOS with L-arginine analogues such as $N^{\mathrm{G}}$-nitro-L-arginine methyl ester (L-NAME) produces doseand time-dependent, profound and sustained increases in blood pressure in rats. ${ }^{17}$ It is curious that, unlike other models of hypertension, chronic NOS inhibition in rats does not seem to produce significant cardiac hypertrophy except after hypertensive nephropathy has developed and plasma renin activity has increased. ${ }^{18}$ In a human study, blocking NOS in normal volunteers with an alternative L-arginine analogue, monomethyl-L-arginine produced a $10 \%$ increase in mean arterial pressure, a $19 \%$ reduction in heart rate and therefore a $46 \%$ increase in total peripheral resistance. The authors also detected an increase in urinary sodium excretion with no change in creatinine clearance. ${ }^{19}$

Further evidence for the importance of eNOS in blood pressure control comes from so-called 'knock-out' mice where the gene for eNOS has been removed by genetic manipulation of embryonic stem cells. ${ }^{20}$ None of the cells of these mice contain the gene for eNOS therefore the endothelial cells cannot express it. As expected, these mice are hypertensive compared to 'wild-type' control mice. When the knock-out mice are exposed to the NOS inhibitor LNAME one might expect no change in their blood pressure as they have no eNOS to block. However, their blood pressure falls when treated with LNAME. This curious observation would suggest that one of the other NOS isoenzymes is producing a vasoconstrictor substance which can be blocked by L-NAME. Alternatively, L-NAME may be having a completely different and unknown action.

\section{Nitric oxide and atherosclerosis}

Endothelium-derived NO is an important anti-atherogenic molecule. It has been shown to reduce platelet and monocyte adhesion to the endothelium, reduce vascular smooth muscle cell proliferation and migration. These are important in the early stages of atherogenesis (see ref 21 for review). Oxidised low density lipoprotein (ox-LDL) is an important pro-atherogenic molecule. It is produced by the enzyme lipoxygenase and taken up by macrophages via the non-receptor-mediated scavenger pathway to form lipid-laden foam cells, which are important later in atherogenesis. NO has been shown to reduce lipoxygenase activity in vitro, ${ }^{22}$ which would reduce the amount of ox-LDL available for the scavenger pathway.

Not only is NO release important in preventing atherogenesis, atheromatous plaques in turn damage the endothelium and reduce NO release. In addition, ox-LDL has been shown to reduce the availability of NO. ${ }^{23}$ This may be achieved by hypercholesterolaemia activating xanthine oxidase which produces the free radical superoxide $\left(\mathrm{O}_{2}^{-}\right)$in excess. ${ }^{24}$ Superoxide interacts with and inactivates NO producing peroxynitrite $\left(\mathrm{OONO}^{-}\right){ }^{25}$. This vicious cycle spirals until a plaque ruptures and vascular occlusion occurs, possibly resulting in a myocardial infarction or a cerebrovascular accident (figure 2). There is evidence in hypercholesterolaemic rabbits that oral administration of the NO precursor L-arginine may break this cycle and cause plaque regression. ${ }^{26}$ There is also evidence from studies in humans that L-arginine improves endothelial function in coronary microcirculation of hypercholesterolaemic patients. ${ }^{27}$ While intravenous administration of $\mathrm{L}$-arginine has been shown to produce symptomatic improvement after one week in patients with peripheral vascular disease, ${ }^{28}$ acute intravenous infusion of L-arginine did not improve cardiovascular performance as measured by working 


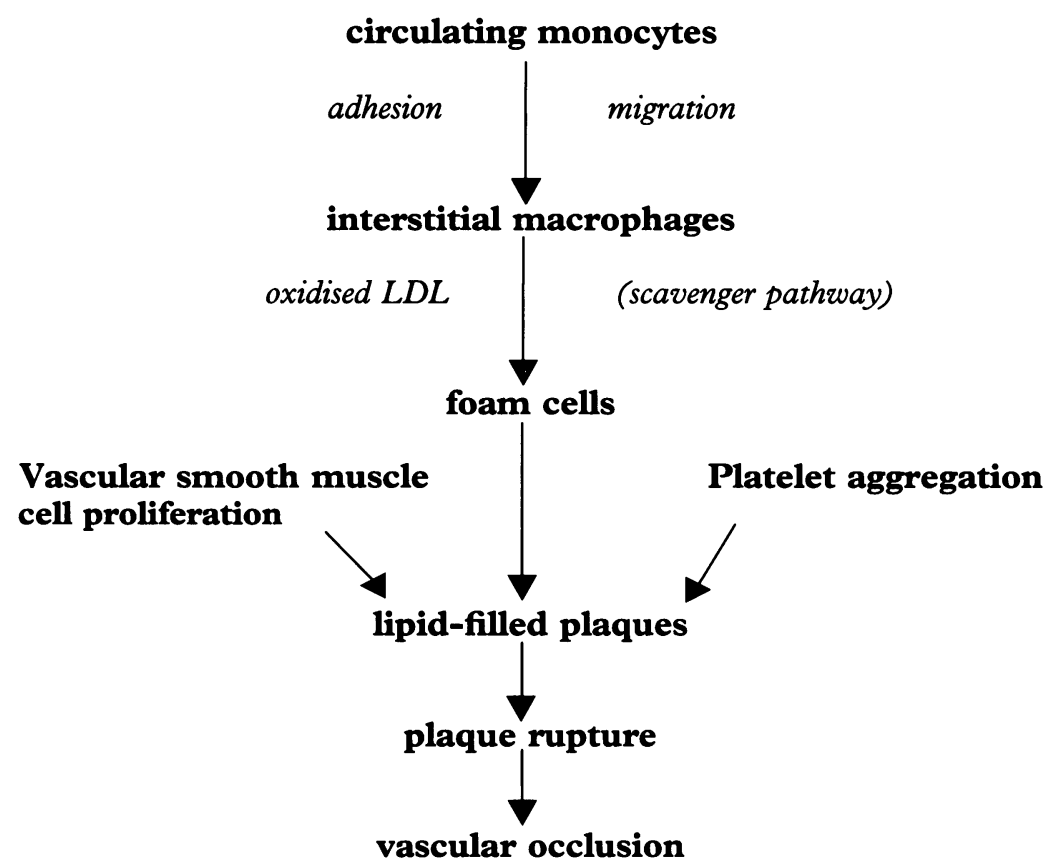

Figure 2 Mechanisms of atherogenesis

capacity indices of myocardial ischaemia in a group of nine hypercholesterolaemic patients. ${ }^{29}$

\section{Smoking, coronary heart disease and NO}

Another interesting study which indirectly implicates NO in atherosclerosis looked at a genetic polymorphism within the human eNOS gene. ${ }^{30}$ The authors identified a rare allele present in only $17 \%$ of a control population with no history or symptoms of coronary artery disease. Only $0.7 \%$ of the control population were homozygous for the rare allele. However, when they genotyped a group of 549 patients consecutively referred for coronary angiography, they found $3.3 \%$ were homozygous for the rare allele, ie, 4.7 times higher than the control population. Not all of the patients referred had significant stenosis (defined as $>50 \%$ occlusion) demonstrable at angiography. In the subgroup of 401 referred who had significant stenosis in one, two or three coronary arteries, the frequency of homozygotes for the rare allele rose to $4.2 \%$, ie, six times as high as the control population. This represents a significant association between homozygosity for the rare allele and coronary artery disease.

Cigarette smoking is a known risk factor for coronary artery disease and also endothelial dysfunction. Therefore, the authors went further and divided the coronary population into smokers (past and present) and non-smokers (never). Among the smokers they found a $35 \%$ excess risk for significant stenosis in one, two or three coronary arteries associated with homozygosity for the rare allele compared to non-smoking homozygotes. While there is as yet no evidence that this polymorphism affects endothelial NOS function, it suggests a geneenvironment interaction whereby there is a genetically determined predisposition to increased smoking-associated coronary risk in subjects homozygous for the rare allele. This may partly explain the anecdotes of some heavy cigarette smokers who never succumb to cardiovascular disease, while others succumb at an early age.

\section{Implications for therapy}

\section{NITROVASODILATORS}

Nitrovasodilators such as glyceryl trinitrate, isosorbide mononitrate and sodium nitroprusside act by releasing ('donating') NO to the vascular smooth muscle. They are therapeutically useful in that they can cause vasorelaxation and hence coronary arteriodilatation in angina pectoris and lower blood pressure. They donate NO by mechanisms involving intracellular thiol groups, which are the sulphur-containing amino acid residues of intracellular proteins. ${ }^{31}$ When these thiol groups are depleted the vascular smooth muscle becomes less responsive to NO donors and 'nitrate tolerance' is said to develop. This can be alleviated by temporary withdrawal of the NO donor which allows replenishment of the 


\section{Proposed mechanisms for cardioprotective effects of oestrogens $^{3}$}

- produce a less atherogenic lipid profile: lower LDL cholesterol, raise HDL cholesterol, lower lipoprotein(a) levels

- increase NO release via upregulation of NOS enzyme

- act as an anti-oxidant: reduce NO inactivation, prevent LDL oxidation, promote collateral angiogenesis via fibroblast growth factor

Box 1 thiol groups or possibly by the use of newer NO donors under development which contain their own thiol groups and are therefore not reliant on intracellular thiol groups to donate NO.

\section{OESTROGENS}

Hypertension and cardiovascular disease are less common in women of reproductive age than in age-matched males. ${ }^{32}$ The precise mechanism for this is not clear, but there is evidence that oestrogens have a beneficial effect on endothelial NO production. At a cellular level, in vitro studies have shown increased levels of eNOS $\mathrm{mRNA}^{33}$ and increased NO release $\mathrm{s}^{34}$ in cultured endothelial cells exposed to the naturally occurring oestrogen $17 \beta$-oestradiol. The latter study demonstrated that this occurred via an oestrogen-receptormediated pathway. Like other steroid hormones, oestrogen binds to cytoplasmic receptors and the resulting complex moves to the nucleus where it interacts with regulatory sequences to activate the transcription of certain genes. ${ }^{35}$ Such oestrogen-responsive regulatory sequences have been identified upstream from the gene encoding eNOS, ${ }^{36}$ providing further evidence that oestrogens may increase eNOS expression.

At a functional level, there are many studies showing improved endothelial function after oestrogen treatment in animal models and post-menopausal women. In addition, oestrogen has been shown to produce a less atherogenic lipid profile with reduced levels of LDL and lipoprotein, and increased levels of high density lipoprotein (HDL). Oestrogen is also thought to act as an antioxidant which would prevent NO inactivation and LDL oxidation (box 1, see ref 37 for review). There are therefore many reasons why oestrogen in the form of hormone replacement therapy may protect post-menopausal women from cardiovascular disease.

\section{GENE THERAPY}

Gene therapy is a technique whereby a defective endogenous gene is supplemented by an exogenous functional copy of the gene. The gene of interest can be cloned into a 'vector' such as a replication-deficient virus and delivered to the tissue of interest where the gene will be expressed. This technique is being applied to a variety of human diseases, most notably those caused by inherited single gene defects. However, there has been much recent interest in the application of such techniques to cardiovascular disease. For the reasons outlined above, over-expression of the NOS gene may be useful in some cardiovascular diseases. Dzau et al have already demonstrated that overexpression of the gene encoding eNOS can reduce undesirable neointimal hyperplasia after balloon injury to rat carotid arteries. ${ }^{38}$ Current methods of gene transfer require further refinement, but one can envisage the future role for local molecular therapeutics to prevent re-stenosis after angioplasty or stent insertion.

\section{Conclusion}

NO, which was at one time regarded as a dangerous air pollutant, is now accepted as an important regulatory molecule of cardiovascular function in health. A relative NO deficiency may contribute to the pathogenesis of hypertension in some experimental models and perhaps also in subgroups of patients with essential hypertension. The latter statement remains controversial and requires further study. There is no doubt that NO is a potent antiatherogenic molecule which can interrupt the pathway to advanced atherosclerosis at many points (box 2). Once the early stages of atherosclerosis have begun, the subsequent endothelial damage makes progression almost inevitable. More research is required into ways of manipulating the L-arginine/NO pathway, either by newer NO donors or gene therapy, which will help attenuate the progression of atherosclerosis.

\footnotetext{
5 Förstermann U, Closs EI, Pollock JS, et al. Nitric oxide synthase isoenzymes. Characterization, purification, molecular cloning, and functions. Hypertension 1994; 23: $1121-31$.

6 Sessa WC, Pritchard K, Seyedi N, Wang J, Hintze TH. Chronic exercise in dogs increase coronary vascular nitric oxide production and coronary nitric oxide synthase endothelial cell nitric oxide synthase gen expression. Circulat Res 1994; 74: $349-53$.

Tolins JP, Palmer RM, Moncada S, Raij L. Role of endothelium-derived relaxing factor in regulation of renal haemodynamic responses. $\mathrm{Am} \mathcal{F}$ Physiol 1990; 258: H655-62.
}

8 Panza JA, Quyyumi AA, Brush JE Jr, Epstein SE. Abnormal endothelium-dependent vascular relaxation in patients with essential hypertension. N Engl f Med 1990; 323: 22-7. Vasodilatation to acetylcholine in primary and secondary forms of human hypertension. Hypertension 1993; 21: 929-33.

10 Treasure CB, Manoukian SV, Klein JL, et al. Epicardial coronary artery responses to acetylcholine are impaired in hypertensive patients. Circ Res 1992; 71: 776-81.
9 Taddei S, Virdis A, Mattei P, Salvetti A -derived nitric oxide on pe 1000.

4 Palmer RMJ, Ashton DS, Moncada S. Vascular endothelial cells synthesise nitric oxide from L arginine. Nature 1988; 333: 664-6. 
11 Linder L, Kiowski W, Buhler FR, Luscher TF. Indirect evidence for release of endothelium-
derived relaxing factor in human forearm circuderived relaxing factor in human forearm circulation in vivo blunted response
Circulation 1990; 81: $176-27$.

12 Calver A, Collier J, Moncada S, Vallance P. Effect of local intra-arterial $N^{\mathrm{G}}$-monomethyl-Larginine in patients with hypertension: the nitric oxide dilator mechanism appears abnormal. $f$ Hypertens 1992; 10: 1025-31.

13 Cockcroft JR, Chowienczyk PJ, Benjamin N, Ritter JM. Preserved endothelium-dependent vasodilatation in patients with essential hypervasodilatation in patients with essential hyper-
tension. $N$ Engl f Med 1994; 330: 1036-40.

14 Laurent S, Lacolley P, Brunel P, Laloux B, Pannier B, Safar M. Flow-dependent vasodilation of brachial artery in essential hypertension. Am f Physiol 1990; 258: H1004-11.

15 Dominiczak AF, Bohr DF. Nitric oxide and its putative role in hypertension. Hypertension 1995; 25: $1202-11$.

16 Nakaki T, Hishikawa $K$, Suzuki H Saruta $T$, Kato R. L-Arginine induced hypotension. Lance 1990; 336: 696 .

17 Ribeiro MO, Antunes E, de-Nucci G, Lovisolo SM, Zata R. Chronic inhibition of nitric oxide synthase. A new model of arterial hypertension. Hypertension 1992; 20: 298-303.

18 Arnal JF, el-Amrani AI, Chatellier G, Menard J, Michel JB. Cardiac weight in hypertension induced by nitric oxide synthase blockade. Hypertension 1993; 22: 380-7.

19 Haynes WG, Noon JP, Walker BR, Webb DJ. Inhibition of nitric oxide synthesis increase blood pressure in healthy humans. $f$ Hyperten 1993; 11: 375-80.

20 Huang PL, Huang Z, Mashimo $\mathrm{H}$, et al. Hypertension in mice lacking the gene for endothelial nitric oxide synthase. Nature 1995 377: $239-42$.

21 Cooke JP, Tsao PS. Is nitric oxide an endogenous antiatherogenic molecule? Arterioscler Thromb 1994; 14: 653-5.
22 Rubbo H, Parthasarathy S, Barnes S, Kirk M, Kalyanaraman B, Freeman BA. Nitric oxide inhibition of lipoxygenase-dependent liposome and low-density lipoprotein oxidation: termination of radical chain propagation reactions and formation of nitrogen-containing oxidised lipid derivatives. Arch Biochem Biophys 1995; 324: $15-25$.

23 Galle J, Busse R, Bassenge E. Effects of native and oxidised low density lipoproteins on formation and inactivation of endothelium-derived relaxing factor. Arterioscler Thromb 1991; 11: relaxing

24 O'Hara Y, Peterson TE, Harrison DG. Hypercholesterolaemia increases endothelial superoxide anion production. $\mathcal{f}$ Clin Invest 1993; 91 : $2546-51$

25 Moro MA, Darley-Usmar VM, Goodwin DA, et al. Paradoxical fate and biological action of peroxynitrite on human platelets. Proc Natl Acad Sci USA 1994; 91: 6702-6.

26 Candipan RC, Wang BY, Buitrago R, Tsao PS, Cooke JP. Regression or progression: dependency on vascular nitric oxide. Arterioscler Thromb Vasc Biol 1996; 16: 44-50.

27 Drexler H, Zeiher AM, Heinzer K, Just $\mathrm{H}$. Correction of endothelial dysfunction in coronary microcirculation of hypercholesterolaemic ary microcirculation of hypercholesterolaemic patients $1546-50$.

28 Gryglewski RJ, Grodzinska L, KostkaTrabka E, et al. Treatment with $\mathrm{L}$-arginine is likely to stimulate generation of nitric oxide in patients with peripheral arterial obstructive disease. Wien Klin Wochenschr 1996; 108: $111-6$.

29 Wennmalm A, Edlund A, Granstrom EF, Wiklund $O$. Acute supplementation with the nitric oxide precursor L-arginine does not improve cardiovascular performance in patients with hypercholesteroaemia. Atherosclerosis 1995; 118: $223-31$.
30 Wang XI, Sim AS, Badenhop RF, McCredie RM, Wilcken DEL. A smoking-dependent risk of coronary artery disease associated with a
polymorphism of the endothelial nitric oxide synthase gene. Nat Med 1996; 2: $41-5$

31 Ignarro LJ, Lipton $\mathrm{H}$, Edwards JC, et al. Mechanism of vascular smooth muscle relaxation by organic nitrates, nitrites, nitroprusside and nitric oxide: evidence for the involvement of $\mathrm{S}$-nitrosothiols as active intermediates. $\mathscr{f} \mathrm{Phar}$ macol Exp Ther 1981; 218: 739-49.

32 Barrett-Connor E, Bush TL. Estrogen and coronary heart disease in women. FAMA 1991; 265: $1861-7$.

33 Goetz RM, Morano I, Calovini T, Studer R, Holtz J. Increased expression of endothelial constitutive nitric oxide synthase in rat aorta during pregnancy. Biochem Biophys Res Commun 1994; 205: 905- 10.

34 Hayashi T, Yamada K, Esaki T, et al. Estrogen increases endothelial nitric oxide by a receptormediated system. Biochem Biophys Res Commun 1995; 214: 847- 55.

35 Smith SS. Female sex steroid hormones: from receptors to networks to performance. Prog Neurobiol 1994; 44: 55-86.

36 Venema RC, Nishida K, Alexander RW, Harrison DG, Murphy TJ. Organisation of the bovine son DG, Murphy TJ. Organisation of the bovine synthase. Biochim Biophys Acta 1994; 3: 413 20.

37 Gerhard M, Ganz P. How do we explain the clinical benefits of estrogen? From bedside to bench. Circulation 1995; 92: 5-8.

38 von der Leyen HE, Gibbons GH, Morishita R, et al. Gene therapy inhibiting neointimal vascular lesion: in vivo transfer of endothelial nitric oxide synthase gene. Proc Natl Acad Sci USA 1995; 92: $1137-41$. 